\title{
PEMBINAAN AKHLAK MULIA PADA SEKOLAH DASAR (Studi Deskriptif Pada Sekolah Dasar Islam Terpadu Nur Al- Rahman)
}

\author{
Selly Sylviyanah,* \\ Program Studi Ilmu Pendidikan Agama Islam, \\ Fakultas Pendidikan Ilmu Pengetahuan Sosial, Universitas Pendidikan Indonesia \\ *Email: selly.sylviyanah@gmail.com
}

\begin{abstract}
ABSTRAK
Akhlak mulia merupakan pondasi utama dalam pembentukkan pribadi manusia. Untuk merealisasikan akhlak mulia dalam kehidupan, perlu adanya suatu pembinaan yang dilakukan secara terus-menerus khususnya pada sekolah dasar. Penelitian ini bertujuan untuk mendeskripsikan upaya-upaya yang dilakukan oleh pihak sekolah khususnya SDIT Nur-al Rahman dalam membina akhlak mulia peserta didiknya. Upaya tersebut meliputi perencanaan, pelaksanaan, serta hasil yang dicapai dari pembinaan akhlak mulia di SDIT Nur al-Rahman. Penelitian ini menggunakan pendekatan kualitatif dengan metode deskriptif. Pertimbangan penggunaan metode ini adalah untuk mengungkapkan realitas dan aktualitas mengenai pembinaan akhlak mulia pada SDIT Nur al-Rahman. Dalam pengumpulan data, peneliti menggunakan empat metode yaitu observasi, wawancara, dokumentasi, dan literatur. Berdasarkan hasil penelitian, diperoleh gambaran mengenai perencanaan pembinaan akhlak mulia yaitu dengan menetapkan indikator atau acuan pembinaan akhlak mulia di sekolah. Indikator tersebut terdiri dari pembiasaan 5S (senyum, salam, sapa, sopan, dan santun) serta janji pelajar Islam. Setelah itu barulah dibentuk team khusus afeksi agar pembinaan tersebut bisa berjalan sesuai dengan yang telah direncanakan. Pelaksanaan pembinaan akhlak mulia pada SDIT Nur al Rahman dilakukan dengan menggunakan tiga metode yaitu pembiasaan, keteladanan, serta pemberian pahala dan sanksi. Orang tua peserta didik pun ikut bekerja sama dengan pihak sekolah dalam pembinaan akhlak anaknya. Faktor pendukung dalam pelaksanaan pembinaan akhlak mulia adalah lingkungan belajar yang kondusif serta religius dengan prasarana yang lengkap dan memadai bagi peserta didik diimbangi dengan pendidiknya yang berkompeten dan sudah pasti dapat dijadikan contoh yang baik bagi peserta didik. Faktor penghambat dalam pelaksanaan pembinaan akhlak mulia adalah kepribadian yang kurang baik dari setiap individu, faktor keluarga, teknologi yang pesat, serta faktor dari pendidik itu sendiri. Hasil dari pembinaan akhlak mulia adalah terbentuknya akhlak mulia peserta didik. Hal ini dapat terlihat pada keseharian peserta didik di sekolah.
\end{abstract}

Kata Kunci: Pembinaan Akhlak; Akhlak Mulia; Pembinaan Akhlak di SD. 


\section{PENDAHULUAN}

Kemajuan ilmu dan teknologi membawa perubahan bagi kehidupan manusia, sejalan dengan perubahan itu, untuk menghindari ketertinggalan dengan bangsa lain maka upaya tepat yang harus dilakukan oleh bangsa Indonesia adalah melakukan pembangunan siaga fisik, mental, material, dan spiritual.

Manusia memiliki sejumlah potensi atau kemampuan yang diberikan Allah SWT. Abdul Mujib menyebutkan tujuh macam potensi manusia yaitu al-Fitrah (cinta asli), ákl (akal) al-Hayyah (daya/tenaga), al-Khuluq (karakter), atTabhú (tabiat), al-Sajiyah (bakat), al-Sifāt (sifat-sifat), dan al-Ámal (perilaku). Untuk mengembangkan potensinya tersebut manusia memerlukan pendidikan. Pendidikan berusaha untuk menampakkan (aktualisasi) potensi-potensi tersebut yang dimiliki oleh setiap peserta didik (Mujib, 2006, hal. 43-48).

Akhlak merupakan pondasi yang utama dalam pembentukkan pribadi manusia seutuhnya. Pendidikan yang mengarah pada terbentuknya pribadi yang berakhlak, merupakan hal pertama yang harus dilakukan. Pembinaan akhlak di sekolah harus dilakukan secara teratur dan terarah agar siswa dapat mengembangkan dan mempraktekkannya dalam kehidupan sehari-hari.

Hal ini sesuai dengan fungsi dan tujuan pendidikan dalam Undang-undang tentang Sistem Pendidikan Nasional Nomor. 20 tahun 2003 bab 1 pasal 1 dijelaskan bahwa:

"Pendidikan adalah usaha sadar dan terencana untuk mewujudkan suasana belajar dan proses pembelajaran agar peserta didik secara aktif mengemban potensi dirinya untuk memiliki kekuatan spiritual keagamaan, pengendalian diri, kepribadian, kecerdasan, akhlak mulia serta keterampilan yang diperlukan dirinya, masyarakat, bangsa dan Negara" (UU Sisdiknas No. 20 tahun 2003).

Berdasarkan Undang-undang di atas jelas tergambarkan bahwa salah satu dari tujuan pendidikan nasional adalah agar peserta didik dapat mengembangkan potensinya sehingga memiliki kekuatan spiritual keagamaan, pengendalian diri, kepribadian, kecerdasan, akhlak mulia serta keterampilan yang tidak hanya diperlukan bagi dirinya tetapi juga untuk masyarakat, bangsa dan negara.

Akhlak merupakan salah satu dari tiga kerangka dasar dalam ajaran Islam. Aqidah, syariah dan akhlak merupakan hal yang saling berkaitan dan tidak dapat terpisahkan. Akhlak merupakan buah yang dihasilkan dari proses penerapan aqidah dan syariah. Ibarat bangunan, akhlak merupakan kesempurnaan dari bangunan tersebut setelah pondasi dan bangunannya kuat. Jadi tidak mungkin akhlak ini akan terwujud pada diri seseorang jika dia tidak memil ki aqidah dan syariah yang baik (Marzuki, 2009, hal. 13).

Nabi Muhammad diutus ke muka bumi ini membawa misi pokok untuk menyempurnakan akhlak manusia yang mulia. Seperti dalam hadisnya:

Artinya: "Sesungguhnya aku diutus (Allah) untuk menyempurnakan akhlak (budi pekerti)”. (HR. Bukhari)

Hadis di atas menjelaskan bahwa misi Nabi ini bukan misi yang sederhana, tetapi misi yang agung dan untuk merealisasikannya diperlukan waktu kurang lebih 22 tahun. Nabi melakukannya 
mulai dengan pembenahan akidah masyarakat Arab, selama 13 tahun, lalu Nabi mengajak untuk menerapkan syariah setelah akidahnya mantap. Dengan kedua sarana inilah (akidah dan syariah), nabi dapat merealisasikan akhlak mulia di kalangan umat Islam (Marzuki, 2009, hal. 13).

Untuk dapat mengamalkan akhlak mulia diperlukan pendalaman tentang konsep akhlak itu sendiri. Dengan pemahaman yang jelas tentang konsep akhlak, kita akan memiliki pijakan dan pedoman untuk mengarahkan tingkah laku kita sehari-hari, apakah yang kita lakukan benar atau tidak, termasuk akhlak mulia atau akhlak tercela.

Akhlak berasal dari bahasa Arab jama' dari Khuluqun yang menurut bahasa diartikan budi pekerti, perangai, tingkah laku atau tabiat. Kalimat tersebut mengandung segi-segi persesuaian dengan perkataan Khalqun yang berarti kejadian, serta erat hubungannya dengan khāliq dengan mäkhluk dan antara mäkhluk dengan mākhluk.

Ibn Miskawaih (dalam Sinaga, 2004, hal. 37) mendefinisikan akhlak sebagai keadaan jiwa seseorang yang mendorongnya untuk melakukan perbuatan- perbuatan tanpa melalui pertimbangan pikiran terlebih dahulu. Sedangkan menurut Imam Ghazali: "Akhlak ialah sifat yang melekat dalam jiwa seseorang yang menjadikan ia dengan mudah bertindak tanpa banyak pertimbangan lagi”. Atau boleh juga dikatakan, perbuatan yang sudah menjadi kebiasaan. Orang yang pemurah sudah biasa memberi. Ia memberi itu tanpa pertimbangan lagi. Seolah-olah tangannya sudah terbuka lebar untuk itu. Hal ini bisa terjadi karena yang bersangkutan sebelumnya telah berlatih, artinya sifat pemurah itu sudah biasa dia lakukan setiap saat.

Secara umum akhlak dibagi menjadi dua yaitu akhlak mulia dan akhlak tercela, akhlak mulia adalah yang harus kita terapkan dalam kehidupan sehari-hari, sedang akhlak tercela adalah akhlak yang harus kita jauhi jangan sampai kita memprakktekannya dalam kehidupan sehari-hari.

Dilihat dari ruang lingkupnya akhlak mulia dibagi menjadi dua bagian, yaitu akhlak terhadap Khāliq (Allah SWT) dan akhlak terhadap mākhluq (selain Allah). Akhlak sesama makhluk masih dirinci lagi menjadi beberapa macam, seperti akhlak terhadap sesama manusia, akhlak terhadap makhluk hidup selain manusia seperi binatang dan tumbuhan, serta akhlak terhadap benda mati (Marzuki, 2009, hal. 22).

Seperti yang telah dijelaskan di atas bahwa kita dapat meneladani akhlak mulia kepada Rasulullah Saw. Karena Rasulullah diutus ke muka bumi membawa misi untuk menyempurnakan akhlak manusia. Namun justru fenomena yang terjadi sekarang ini adalah terjadinya krisis akhlak pada umat Islam. kenyataannya manusia Indonesia khususnya anak-anak dan remaja saat ini kurang dibekali dengan pembinaan akhlak. Hal ini tercermin dari perilaku yang tidak menghormati nilai- nilai kemanusiaan seperti terjadi tawuran remaja, kurang menghormati orang tua, kurang mentaati norma-norma keluarga, hidup tidak disiplin. Terlebih pada masa globalisasi manusia Indonesia cenderung berperilaku keras, cepat dalam menyelesaikan sesuatu, dan budaya instan. Manusia dipaksa hidup seperti robot, selalu berada pada persaingan tinggi (konflik) dengan sesamanya, hidup bagaikan roda berputar cepat, yang membuat manusia mengalami disorientasi 
meninggalkan norma-norma universal, menggunakan konsep Machiavelli (menghalalkan segala cara), mementingkan diri sendiri dan tidak memiliki akhlak yang baik, tidak menghargai, peduli, mengasihi dan mencitai sesamanya.

Untuk merealisasikan akhlak mulia dalam kehidupan, perlu adanya suatu pembinaan yang secara terus menerus dilakukan. Tidak hanya dalam ruang lingkup keluarga saja namun sekolah pun ikut terlibat di dalamnya sebagai tempat pembentukkan kepribadian Islam yang berdasarkan akhlak mulia. Umat Islam diharapkan tidak saja hanya menguasai ilmu pengetahuan dan teknologi yang senantiasa mengalami perkembangan pesat, tetapi juga harus didasari dengan pondasi akhlak yang mulia.

Pembinaan akhlak sangat penting dilakukan sejak dini pada setiap jenjang pendidikan khususnya pada sekolah dasar yang merupakan tahapan terpenting dari perkembangan peserta didik bahkan menjadi hal yang sangat fundamental bagi kesuksesan perkembangan pendidikan peserta didik selanjutnya, karena nasib suatu bangsa ditentukan oleh generasi muda sebagai penerusnya (Rumini, 2004, hal. 15).

Masa sekolah dasar secara ilmiah memiliki rasa keingintahuan yang tinggi dan tertarik akan kehidupan dunia sekitar yang ada di sekelilingnya. Anak sekolah dasar memiliki perkembangan fisik dan motorik, tak tekecuali perkembangan kepribadian, watak, intelektual, budi pekerti dan bahasa yang pesat. Pada anak usia dasar inilah sangat tepat dilakukan pembinaan dan penanaman akhlak mulia sebagai bekal yang akan mereka bawa untuk membangun suatu bangsa yang cerdas menguasai ilmu pengetahuan yang tinggi dan yang paling terpenting adalah berakhlak mulia.

Berdasarkan latar belakang tersebut, Penulis merasa tertarik untuk meneliti tentang "pembinaan akhlak mulia pada sekolah dasar khususnya pada Sekolah Dasar Islam Terpadu Nur al-Rahman". Pertanyaan pokok ini dijabarkan dalam tiga pertanyaan penelitian. (1) Bagaimana perencanaan pembinaan akhlak mulia pada SDIT Nur al-Rahman. (2) Bagaimana pelaksanaan pembinaan akhlak mulia pada SDIT terpadu Nur al-Rahman. (3) Bagaimana hasil pembinaan akhlak mulia pada SDIT Nur al-Rahman.

\section{METODE}

Penelitian ini menggunakan pendekatan kualitatif dengan menggunakan metode deskriptif Pertimbangan penggunaan metode ini adalah untuk mengungkapkan realitas dan aktualitas mengenai pembinaan akhlak mulia pada SDIT Nur al-Rahman. Dalam pengumpulan data, peneliti menggunakan empat metode yaitu observasi, wawancara, dokumentasi, dan literatur.

\section{HASIL DAN PEMBAHASAN}

\section{A. Perencanaan Pembinaan Akhlak Mulia di SDIT Nur Al-Rahman}

Perencanaan pembinaan akhlak mulia pada SDIT Nur al-Rahman di susun berdasarkan visi, misi tujuan dan target pembelajaran.

\section{a. Visi}

Visi SDIT Nur al-Rahman adalah berakhlak mulia, mandiri dan unggul dalam prestasi menuju insan Indonesia bermartabat, cerdas komperhensif dan kompetitif. 
b. Misi

Misi SDIT Nur al-Rahman adalah sebagai berikut:

1) Menerapkan nilai-nilai Islam dalam sistem pendidikan dengan semangat dakwah berdasarkan $\mathrm{Al}$ Qurán dan Al-Hadis

2) Meningkatkan kesiapan input, kualitas proses pendidikan untuk mengoptimalkan output yang unggul

3) Mengelola lembaga pendidikan secara amanah dan professional

4) Memfasilitasi pengembangan potensi anak untuk menjadi pribadi bermartabat, mandiri dan siap berkompetisi

5) Mengembangkan sekolah model yang berwawasan global dan rahmatan lil'alamin.

c. Target pembelajaran

Target pembelajaran (Cerdas Komprehensif) Akhlak Mulia.

SQ

- Berjiwa tauhid

- Aqidah yang lurus

- Sadar sholat EQ

- Meneladani Rasulullah

- Berperilaku santun

- Birulwaliain

- Disiplin

- Percaya diri

- Rapih dan bersih

Mandiri (PQ)

- Fisik yang sehat dan kuat

- Terampil olahraga

- Terampil seni budaya

- Teater

- Tanggung jawab

- Entrepreneur
Prestasi (IQ)

- Ujian nasioanal 8,00

- Tahfidz Qurán 2 juz

- Tartil baca al Qurán

- Membaca efektif

- Berkomunikasi baik

- Karya ilmiah

Setelah itu ditetapkanlah indicator pembinaan akhlak mulia berdasarkan visi, misi, dan target pembelajaran di atas.

Tabel 1

Indikator Pembinaan Akhlak Mulia SDIT Nur Al-Rahman

\begin{tabular}{|c|c|c|}
\hline No & Indikator & Ket. \\
\hline 1 & $\begin{array}{l}\text { Konsep 5 S (Senyum, } \\
\text { Salam, Sapa, Sopan, dan } \\
\text { Santun) }\end{array}$ & \\
\hline 2. & $\begin{array}{l}\text { Janji Pelajar Islam: } \\
\text { - Taat kepada Allah dan } \\
\text { Rasulullah } \\
\text { - Menghormati orangtua } \\
\text { dan guru } \\
\text { - Rajin belajar dan giat } \\
\text { menuntut ilmu } \\
\text { - Menghormati orang yang } \\
\text { lebih tua dan menyayangi } \\
\text { orang yang lebih muda } \\
\text { - Menjaga ketertiban dan } \\
\text { kebersihan di sekolah, } \\
\text { rumah dan masyarakat } \\
\text { - Bersikap mandiri, patuh } \\
\text { dan berakhlak mulia }\end{array}$ & \\
\hline
\end{tabular}

Indikator di atas kemudian di implementasikan dalam proses pendidikan sehari- hari di sekolah. Karena SD Nur alRahman merupakan sekolah Islam yang sifatnya terpadu, maka pembinaan akhlak mulia mencakup dalam seluruh aspek pembelajaran baik di kelas maupun di luar kelas. Kegiatan pembinaan akhlak tersebut meliputi:

a. Menerapkan Asmaul Husna values

b. Şalat berjamaah di masjid

c. Pembiasaan shaum Sunnah 
d. Membaca dan menghafal al Qurán

e. Hidup bersih dan disiplin

f. Berprilaku sopan santun kepada orang tua, guru, teman dan lingkungan

g. Melakukan kerja sama orang tua dengan sekolah

Untuk mewujudkan akhlak mulia di SDIT Nur al-Rahman selain dalam hal perencanaan diperlukan juga adanya tim khusu agar kegiatan tersebut dapat berjalan sesuai dengan yang telah direncanakan.

Pembinaan akhlak mulia di SDIT Nur al-Rahman merupakan tanggung jawab seluruh komponen yang terlibat dalam proses pendidikan. Namun secara khusus, pembinaan akhlak termasuk ke dalam bidang afeksi dan konseling yang berada dalam tanggung jawab wakil kepala sekolah bagian kesiswaan. Dalam bidang ini peserta didik terus menerus dibina, diawasi, diarahkan sikap dan perilakunya agar benar-benar memiliki akhlak mulia tidak hanya diamalkan dalam ruang lingkup sekolah saja, tetapi juga dalam keluarga dan masyarakat.

Selain bidang afeksi langsung yang menangani pembinaan akhlak tersebut, peserta didik pun ikut dilibatkan dalam upaya pembinaan akhlak mulia yang tergabung dalam kelompok" Penegak Disiplin Siswa" (PDS). Mereka adalah peserta didik yang terpilih dari kelas 3 sampai kelas 6 berdasarkan kepribadian dan sikap mereka sehari-hari di sekolah.

Agar pembinaan akhlak mulia berjalan dengan terarah maka dibuatlah tata tertib untuk peserta didik yaitu:

- Siswa hadir pukul 07.00 untuk mengikuti kegiatan riyadhoh (olahraga bebas) dan paling lambat hadir yam 07.10
- Apabila terlambat selama 3x berturut-turut, siswa akan mendapat pembinaan

- Pemanggilan orang tua akan dilakukan apabila sampai $4 \mathrm{x}$ berturut-turut siswa masih terlambat datang

- Bila siswa tidak masuk, maka wajib memberitahukannya pada wali kelas/guru kelas dengan alas an yang jelas dari orang tuanya

- Buku penghubung wajib diisi dan dibawa setiap hari

- Siswa memakai pakaian sesuai jadwal

- Siswa tidak boleh memakai perhiasan yang berlebihan

- Siswa tiak diperkenankan membawa HP dan elektronik lainnya

- Siswa tidak diperkenankan membawa komik, mainan dan peralatan yang berbahaya

- Jika selama 3 hari berturut-turut siswa tidak masuk sekolah tanpa ada pemberitahuan, orang tua akan dipanggil ke sekolah

- Siswa wajib ikut merawat dan memelihara sarana dan prasarana sekolah

- Siswa tidak diperkenankan keluar dari lingkungan pendidikan selama jam sekolah

- Siswa kelas 3-6 wajib Şalat dzuhur dan ashar berjamaah di masjid Nur al-Rahman

- Siswa memakai seragam lengkap, bersih, dan rapih

- Siswa membiasakan diri mengucapkan salam dan berjabat tangan ketika datang dan pulang saat bertemu guru dan temannya

- Siswa bersikap sopan kepada guru dan orang tuanya 
- Siswa tidak diperkenankan menulis dan berbicara yang tidak baik.

\section{B. Pelaksananaan Pembinaan Akhlak Mulia di SDIT Nur Al- Rahman}

Pelaksanaan pembinaan akhlak

mulia di SDIT Nur al-Rahman tidak dibebankan sepenuhnya kepada guru PAI. Kalau di sekolah dasar pada umumnya, masalah yang berkaitan demgam pembinaan akhlak menjadi tanggung jawab guru PAI. Ketika seorang anak melakukan hal-hal atau tindakan yang tidak baik maka yang disalahkan adalah guru PAI yang ada di sekolah tersebut.

Namun lain halnya pada SDIT Nur al-Rahman yang menerapkan sistem pembelajaran terpadu. Semua pendidik bekerja sama untuk membina akhlak peserta didik. Akhlak mulia tidak hanya mencakup sebagian kecil dari mata pelajaran PAI, namun terintegrasikan pada semua pelajaran umum dan kegiatan ekstrakulikuler.

Dalam pelaksanaannya, SDIT Nur al-Rahman tetap mengacu pada Undangundang sistem pendidikan nasional dengan penambahan materi atau muatan khas yang disesuaikan dengan kondisi dan lingkungan sekolah. Pembinaan akhlak mulia menapat perhatian khusus dari pihak sekolah. pembinaan tersebut dilakukan melalui tiga metode yaitu pembiasaan, keteladanan, serta pahala dan sanksi.

\section{Hasil Pembinaan Akhlak Mulia di SDIT Nur Al-Rahman}

Hasil pembinaan akhlak mulia di

SDIT Nur al-Rahman dilihat dari perubahan sikap dan tingkah laku selama masa pendidikan di al-Rahman. Memang sangat susah untuk mengukur tingkah laku peserta didik sehingga dikatakan telah berakhlak mulia.

Hasil yang telah dicapai dari pembinaan akhlak mulia tersebut dapat penulis lihat melalui observasi langsung dalam keseharian peserta didik di sekolah baik saat berada di kelas ketika proses belajar berlangsung maupun di luar kel $\mathrm{s}$ ketika mereka istirahat.

\section{KESIMPULAN}

Berdasarkan hasil penelitian dan pembahasan yang telah disampaikan pada bab IV, berikut akan dikemukakan beberapa kesimpulan yang dapat diambil mengenai pembinaan akhlak mulia di SDIT Nur al-Rahman.

Upaya pembinaan akhlak mulia yang dilakukan pada SDIT Nur al-Rahman meliputi perencanaan serta pelaksanaan. Perencanaan pembinaan akhlak mulia dilakukan dengan menetapkan indikator, tujuan, serta ruang lingkup akhlak mulia yang perlu dibina oleh SDIT Nur alRahman. Akhlak mulia tersebut yaitu akhlak mulia kepada Allah seperti Şalat, membaca al Qurán, serta akhlak mulia kepada sesama manusia (orang tua, guru, teman).

Pelaksanaan pembinaan akhlak mulia pada SDIT Nur al-Rahman menggunakan tiga metode yaitu pembiasaan, keteladanan, serta pemberian pahala dan sanksi (reward dan punishment). Metode pembiasaan meliputi pembisasaan menerapkan asmaul husna values, 5S (Senyum, salam, sapa sopan dan santun), berinteraksi dengan al Qurán melalui tilawah tahfiz Qurán (TTQ), Şalat berjamaah di masjid, sahum sunah, serta membiasakan hidup bersih dan disiplin.

Dalam pelaksanan pembinaan akhlak mulia pada SDIT Nur al-Rahman selain dilakukan oleh pihak sekolah sebagai 
pendidik, orang tua peserta didik ikut bekerjasama dengan pihak sekolah yaitu dengan menuliskan perkembangan anaknya pada buku penghubung yang berupa amalan sehari-hari seperti Şalat dan membaca al Qurán. Hal ini dimaksudkan agar pihak sekolah dapat memantau perkembangan siswa dirumah maupun di lingkungan tempat tinggalnya.

Faktor pendorong pembinaan akhlak mulia pada SDIT Nur al-Rahman diantaranya yaitu lingkungan sekolahnya yang kondusif untuk menciptakan suasana pendidikan yang berakhlak mulia. Bisa kita lihat dengan adanya masjid yang berada dalam satu lingkungan sekolah. Hal ini menciptakan suasana religius bagi peserta didik dimana fungsi masjid bukan hanya sebagai sarana beribadah saja, tetapi juga sebagai tempat untuk belajar dan menanamkan nilai-nilai akhlak mulia kepada peserta didik. Sumber daya manusia yang tidak lain adalah pendidiknya pun adalah orang-orang yang sangat berkompeten dalam bidangnya yang dapat dijadikan panutan dan teladan bagi peserta didik.

Faktor penghambat dalam pembinaan akhlak mulia pada SDIT Nur alRahman adalah dari kepribadian individu peserta didik, keluarga, teknologi yang semakin berkembang serta dari guru/pendidiknya.

Hasil dari pembinaan akhlak mulia pada SDIT Nur al-Rahman adalah tebentuknya akhlak mulia peserta didik. Hal ini dapat dilihat pada interaksi antara pendidik, ketika proses belajar di kelas berlangsung maupun ketika sedang berada di luar kelas para peserta didik tetap menjaga sikap mereka baik dengan pihak sekolah maupun teman-temannya. Pembinaan yang terus menerus dilakukan akan membentuk akhlak mulia peserta didik yang ditandai dengan kesadaran mereka untuk melakukan hal-hal yang baik berdasarkan tanpa disuruh atau diperintah oleh pendidik atau pihak sekolah.

Melihat sejumlah temuan yang diperoleh dari hasil penelitian tentang pembinaan akhlak mulia pada SDIT Nur alRahman, maka dengan ini peneliti memberikan rekomendasi yang mudahmudahan bermanfaat khususnya bagi SDIT Nur al-Rahman.

1. Untuk melaksanakan pembinaan akhlak mulia diperlukan peran aktif serta komitmen dari seluruh warga sekolah .

2. Untuk team afeksi siswa lebih terkordinasi dan ditingkatkan lagi kinerjanya, salah satunya adalah dengan menambahkan sumber daya manusia dalam team afeksi agar pembinaan peserta didik dapat berlangsung secara efektif juga efisien.

3. Kepada pendidik agar lebih dicarikan solusi atau alternatif lain dalam membina akhlak mulia peserta didiknya dengan cara yang menyenangkan dan langsung mengena di hati peserta didik karena terkadang peserta didik merasa jenuh dengan banyaknya aturan dan tata tertib di sekolah.

4. Kepada peserta didik agar senantiasa belajar dengan sungguh-sungguh dan berusaha mengembangkan potensi yang ada dalam diri masing-masing 


\section{REFERENSI}

----. (2008). Al-Qur'anul Karim. (Y. P.

Qur'an, Penerj.) Bandung: CV

Dipenogoro.

Al-Ghazali, I. (1995). Teosofia Al-Qur'an. Surabaya: Risalah Gusti.

al-Hilali, M. (2011). Agar Al-Quran Menjadi Teman. Jakarta: Zaman.

Arikunto, S. (2005). Manajemen Pendidikan. Jakarta: Rineka Cipta.

Depdiknas. (2003). Standar Kompetensi Mata Pelajaran Pendidikan Agama Islam SD \& MI. Jakarta: Pusat Kurikulum, Balitbang Depdiknas.

Majid, D. A. (2006). Pendidikan Agama Islam Berbasis Kompetensi. Bandung: PT Remaja Rosda Karya.

Marzuki. (2009). Prinsip Dasar Akhlak Mulia. Yogyakarta: Debut Wahana Press.

Masykuri. (2007). Studi Tentang

Pembinaan Akhlak Siswa pada Madrasah Tsanawiyah YASPURI Merjosari Kota Malang. Malang.

Moleong, L. (2010). Metodologi Penelitian Kualitatif. Bandung: PT Remaja Rosda Karya.

Mujib, A. (2006). Ilmu Pendidikan Islam. Jakarta: Kencana.

Munawwir, A. W. (2007). Kamus ArabIndonesia. Yogyakarta: PP AlMunawwir.

Nasution, S. (2006). Penelitian Ilmiah. Jakarta: Bumi Aksara.
Nata, A. (2003). Akhlak Tasawuf. Jakarta: Raja Grafindo Prasada.

Ramayulis. (2008). Ilmu Pendidikan Islam. Jakarta: Kalam Mulia.

Rumini, S. (2004). Perkembangan Anak dan Remaja. Jakarta: Rineka Cipta.

Sa'aduddin, I. A. (2006). Meneladani Akhlak Nabi. Bandung: PT Remaja Rosda Karya.

Sinaga, Z. A. (2004). Pengantar Studi Akhlak. Jakarta: Raja Grafindo Persada.

Soehartono, D. I. (2008). Metode Penelitian Sosial. Bandung: PT Remaja Rosda Karya.

Sudjana, D. (2008). Evaluasi Program Pendidikan Luar Sekolah. Bandung: PT Remaja Rosda Karya.

Sudjana, D. (2010). Manajemen Program Pendidikan. Bandung: PT Remaja Rosda Karya.

Sultani, G. R. (2004). Hati Yang Bersih Kunci Ketenangan Jiwa. Jakarta: Pustaka Zahra.

Surakhmad, W. (1998). Pengantar Metodologi Ilmiah. Bandung: Tarsito.

Tanpa Nama. (2010). Undang-Undang SISDIKNAS (Sistem Pendidikan Nasional). Bandung: Fokusmedia.

Yin, P. D. (2009). Studi Kasus Desain dan Metode. Jakarta: Rajawali Press.

Yunahar, I. (2004). Kuliah Akhlak. Yogyakarta: LPPI UMY. 